\title{
Long-Term Stability and Durability of High-Temperature Alloys
}

\author{
CHANTAL K. SUDBRACK ${ }^{1,3}$ and MARK C. HARDY ${ }^{2,4}$ \\ 1.-NASA Glenn Research Center, Cleveland, OH, USA. 2.-Rolls-Royce plc, Derby, UK. \\ 3.—e-mail: chantal.k.sudbrack@nasa.gov. 4.—e-mail: mark.hardy@rolls-royce.com
}

This JOM topic addresses long-term stability and durability of high-temperature alloys, and it is sponsored by the TMS High Temperature Alloys Committee. Over the past year, the committee has supported more than half a dozen symposia at the TMS 2013 Annual Meeting, MS\&T 2014 meeting, and TMS 2014 Annual Meeting. Members of the committee worked with symposia organizers to identify meeting presentations that best represented some of the most exciting and interesting developments in this topic area. Most articles contained herein are contributions from the following symposia: Materials for High-Temperature Applications: Next-Generation Superalloys and Beyond (TMS2014), High-Temperature Gamma(f.c.c.)/ Gamma-Prime( $\mathrm{L}_{2}$ structure) Co-Al-W Based Superalloys (TMS2014), and Long-Term Stability of High-Temperature Materials (TMS2014).

Near-future gas jet engine designs are expected to achieve increasingly higher levels of fuel economy and reduced emissions, placing significant demands on alloy long-term stability and durability needed to accommodate higher service temperatures and stresses within the engine's high-pressure turbine (HPT) section. Key HPT components are fabricated from Ni-based superalloys, which derive their excellent high-temperature mechanical properties from a dispersion of $\mathrm{Ni}_{3} \mathrm{Al}$-based $\mathrm{L}_{2}$-ordered precipitates $\left(\gamma^{\prime}\right)$ within Cr-enriched disordered fcc solid solution $(\gamma)$. To meet the future design demands, new alloy systems, with the potential to surpass the properties of existing $\gamma^{\prime}$-superalloys, are being pursued. Two such alloy systems include ternary eutectic $\gamma-\gamma^{\prime}-\delta$ Ni-based superalloys and Co-based $\gamma^{\prime}$-superalloys. The ternary eutectic $\gamma-\gamma^{\prime}-\delta$ Ni-based superalloys leverage a high-volume fraction of blocky $\mathrm{D}_{\mathrm{a}} \mathrm{Ni}_{3} \mathrm{Nb}$-precipitates $(\delta)$ for composite

Chantal K. Sudbrack and Mark C. Hardy are the guest editors for the High Temperature Alloys Committee of the TMS Structural Materials Division, and coordinators of the topic Long-Term Stability and Durability of High-Temperature Alloys in this issue. strengthening, while Co-based superalloys with $\mathrm{Co}_{3}(\mathrm{~W}, \mathrm{Al}) \gamma^{\prime}$-precipitates may yield better hightemperature creep resistance.

Gaining fundamental thermodynamic and kinetic understanding is relevant to the long-term stability of new multiphase alloy systems, materials databases for designing these alloys computationally, and investigation of the effects of compositional deviations on microstructure. Martin Detrois and coworkers investigate these phenomena in a set of experimental eutectic Ni-based superalloys where the $\mathrm{Ti}$ and Ta contents were intentionally and systematically varied to obtain alloys in which $\delta$ and/or $\eta$ phase precipitates were formed, where $\eta$ is $\mathrm{Ni}_{3} \mathrm{Ti}$ or $\mathrm{Ni}_{3}(\mathrm{Al}, \mathrm{Nb})$-based $\mathrm{DO}_{24}$-ordered precipitates. Comparing these new data with existing data on eutectic $\gamma-\gamma^{\prime}-\delta$ Ni-based superalloys, a phase predominance map is acquired and compositional relationships to predict $\delta$ and $\eta$ formation described.

The high-temperature potential of Co-based $\gamma^{\prime}$-superalloys has made them potentially attractive for single-crystal turbine blade applications. For blade applications, an elevated solvus temperature is essential to maintain high-temperature microstructural stability; yet few of the model alloys discovered to date have achieved solvii above $1100^{\circ} \mathrm{C}$. Notable exception includes the work of $\mathrm{F}$. Xue and coworkers on quinary Co-Al-W-Ta-Ti superalloys. Here, these authors look at the individual and combined effect of Ta and Ti additions on the long-term microstructural stability, creep behavior, and associated post-crept microstructure of Co-Al-W $\gamma^{\prime}$-superalloys. They also elucidate features of the tensile creep deformation mechanism at $900^{\circ} \mathrm{C}$ to $1000^{\circ} \mathrm{C}$ at relevant loads.

Similar to blade alloys, there is concern that the temperature capability of Ni-based polycrystalline alloys for disk and static applications is plateauing. In alloy development of modern disk alloys fabricated by powder metallurgy, key properties include density, environmental resistance, and long-term durability. Matthias Knop and coworkers introduce here V208C, a new polycrystalline Co-Ni $\gamma^{\prime}$-super- 
alloy strengthened with $\gamma^{\prime}-\mathrm{Co}_{3}(\mathrm{Al}, \mathrm{W})$-precipitates. V208C has comparable density to existing polycrystalline Ni-based alloys. V208C also has roughly equal amounts of $\mathrm{Co}$ and $\mathrm{Ni}$, a lower $\mathrm{W}$ content than most model Co $\gamma^{\prime}$-superalloys, and non-negligible amounts of $\mathrm{Al}$ and $\mathrm{Cr}$ for environmental resistance.

Processing of nickel-based superalloys for aerospace applications often includes shot peening after machining, to introduce surface compressive residual stresses and work hardening that can prevent surface fatigue crack nucleation. Temperatures, loading, and mechanical property requirements vary with location in nickel-base superalloy turbine disks. Advances associated with dual microstructure heat treat (DMHT) technology have led to disks fabricated with a fine grain bore in combination with coarse grain web and rim. Olivier Messé and coworkers focus on the effect of shot-peening on fatigue of a coarse-grained disk superalloy RR1000. Their investigation uses a cutting-edge characterization technique to reveal in detail the microstructure and deformation mechanisms associated with fatigue of the shot-peened superalloy.

As the operating temperatures of nickel disk alloys exceed $700^{\circ} \mathrm{C}$ in aircraft engines, there is an increasing potential for surface degradation from hot corrosion and oxidation. Such environmental damage may crack if subjected to in-phase or out-ofphase thermo-mechanical fatigue loading. Benjamin Foss and coworkers have characterized oxidation and oxygen transport in a fine grain disk microstructure using isotopic tracing, using ${ }^{18} \mathrm{O}^{2}$, combined with focused ion beam (FIB) and secondary ion mass spectroscopy (SIMS). Their work reports the influence of stress and surface condition on oxidation and oxygen transport.

Superalloy 718 and its derivatives have found wide success in a variety of turbine engine applications, including both rotating and static components. This success is largely due to a combination of good strength, weldability, castability, and workability at moderate cost. Linear friction welding (LFW) can be an attractive process for joining or repair of aerospace components. K.R.Vishwakarma and coworkers demonstrate successful ATI 718Plus ${ }^{\circledR}$ to 718 Plus ${ }^{\circledR}$ welds with LFW. Their article focuses on characterizing the 718Plus ${ }^{\circledR}$ microstructure after LFW and the standard postweld heat treatment. Secondary carbides, carbonitrides, and $\delta-\mathrm{Ni}_{3} \mathrm{Nb}$ within the as-welded thermomechanically affected zone establish liquid phase reactions during the LFW. Before and after heat treating, this zone remains crack free, which is discussed in more detail.

Precipitation strengthened, polycrystalline Ni-based alloys are also required in boiler superheaters and reheaters for delivering steam to turbines under advanced ultrasupercritical (A-USC) conditions, up to $750^{\circ} \mathrm{C}$. These conditions are necessary for producing greater efficiency in electric power generation and to incorporate clean coal technology. Kinga Unocic and coworkers have characterized the microstructural changes of one such precipitation strengthened alloy, Inconel $740^{\circledR}$, after long-term exposure (up to 3.5 years) in the presence and absence of stress. In particular, the precipitation of $\eta$ phase and the coarsening of the precipitation strengthening phase $\gamma^{\prime}$ were studied as these changes in microstructure are likely to affect creep behavior.

The mission of the TMS High Temperature Alloys Committee is to provide a means of communication among those interested in superalloys and other high-temperature alloys. Emphasis is placed on communicating new technical information and critical reviews on the technology of high-temperature alloys. Symposia concerning high-temperature alloy topics are usually sponsored by the committee at TMS annual and MS\&T meetings, with content exemplified by the informative articles included here. The High Temperature Alloys Committee website provides ample additional information at http://members.tms.org/admin.html?divisions/CHP list.asp. The committee usually meets on Tuesday evening at the TMS annual meeting each spring and MS\&T meeting each fall. All researchers working on high-temperature alloys are invited to attend and participate.

The following articles being published under the topic of Long-Term Stability and Durablity of HighTemperature Alloys provide excellent details and research on the subject. To download any of the articles, follow the url http://link.springer.com/jour nal/11837/66/12/page/ 1 to the table of contents page for the December 2014 issue (vol. 66, no. 12):

- "Precipitate Phase Stability in $\gamma-\gamma^{\prime}-\delta-\eta$ Ni-Base Superalloys," Martin Detrois, Stoichko Antonov, Randolph C. Helmink, and Sammy Tin

- "Improved High-Temperature Microstructural Stability and Creep Property of Novel Co-Base Single-Crystal Alloys Containing Ta and Ti," F. Xue, H.J. Zhou, and Q. Feng

- "A New Polycrystalline Co-Ni Superalloy," M. Knop, P. Mulvey, F. Ismail, A. Radecka, K.M. Rahman, T.C. Lindley, B.A. Shollock, M.C. Hardy, M.P. Moody, T.L. Martin, P.A.J. Bagot, and D. Dye

- "Characterization of Plastic Deformation Induced by Shot-Peening in a Ni-Base Superalloy," O.M.D.M. Messé, S. Stekovic, M.C. Hardy, and C.M.F. Rae

- "Oxidation of a Commercial Nickel-Based Superalloy under Static Loading," B.J. Foss, M.C. Hardy, D.J. Child, D.S. McPhail, and B.A. Shollock

- "Microstructural Analysis of Linear FrictionWelded 718 Plus Superalloy," K.R. Vishwakarma, O.A. Ojo, P. Wanjara, and M.C. Chaturvedi

- "Microstructural Changes in Inconel ${ }^{\circledR} 740$ after Long-Term Aging in the Presence and Absence of Stress,” K. Unocic, H. Wang, J.P. Shingledecker, and P.F. Tortorelli 